\title{
Bernardin de Saint-Pierre oder vom Naturstudium zum Roman
}

Ohne den Kontext des Kolonialismus und die von ihm mitbedingte Sicht des Fremden, des Anderen sowie die mit ihm verbundene Möglichkeit, das Eigene und mehr noch das Andere im Eigenen auf das Andere zu projizieren, ist einer der berühmtesten Romane der französischen Literaturgeschichte nicht zu begreifen. Denn was sich auf der Ile de France - keineswegs in der Kernregion um die Hauptstadt Paris, sondern auf einer weit vom Zentrum Frankreichs entfernten Insel im Indischen Ozean, die wir auch unter der Bezeichnung Mauritius kennen - in romanesker Fügung abspielt, ist just eine solche Projektionsform des eigenen Anderen in das andere Eigene. Denn in die Welt des Anderen, welche durch den europäischen beziehungsweise französischen Kolonialismus zur eigenen geworden ist, wird das Eigene hineinprojiziert und erscheint so, in der Travestie des Eigenen, als einer französischen Leserschaft auf unheimliche Weise vertraut. Sehen wir uns die einzelnen Bestandteile dieser französischen Projektion von Universalität auf das zum Eigenen gewordene Andere einmal detailliert an!

In Bernardin de Saint-Pierres Roman Paul et Virginie sind die drei zentralen Aspekte unserer Annäherungen im Modus der Romanfiktion auf wunderbare Weise miteinander verwoben. Denn beispielhaft verbinden sich das Verhältnis von Besonderem und Allgemeinem, von Partikularität und Universalität, mit einem sich verändernden Verhältnis von Raum und Zeit unter dem Stichwort der ,Verzeitlichung“ sowie auch mit dem dritten Bereich der Herausbildung einer modernen Subjektivität zu einer Fiktion, die ein ungeheures Leserinteresse entfachte. Bis auf den heutigen Tag ist Paul et Virginie aus den Buchläden nicht verschwunden. ${ }^{1}$

Die Entwicklung vom Reisebericht und umfangreichen Naturstudien hin zur Fiktionalität des Romans zeigt eine Reihe von Veränderungen auf, die - so könnten wir zumindest perspektivisch behaupten - auf ein grundlegend verändertes raum-zeitliches Bewusstsein und damit eine Temporalisierung verweisen, die von der Spatialisierung des Denkens im Reisebericht zur Verzeitlichung und in gewisser Weise auch zur Historisierung im Roman führen sollte. Den Bericht von der Reise des Bernardin de Saint-Pierre auf die damals zu Frankreich gehörende

\footnotetext{
$1 \mathrm{Zu}$ Bernardins Roman vgl. Hudde, Hinrich: Bernardin de Saint-Pierre: „Paul et Virginie“. Studien zum Roman und seiner Wirkung. München: Fink 1975; sowie ders.: Zum Einfluß von Bernardin de Saint-Pierres „Paul et Virginie“ auf Romane über die Negersklavenproblematik. In: San Miguel, Angel / Schwaderer, Richard / Tietz, Manfred (Hg.): Romanische Literaturbeziehungen im 19. und 20. Jahrhundert. Festschrift für Franz Rauhut zum 85. Geburtstag. Tübingen: Gunter Narr Verlag 1985, S. 157-167.
}

2 Open Access. (c) 2021 Ottmar Ette, publiziert von De Gruyter. (c))BY-NC-ND Dieses Werk ist lizensiert unter einer Creative Commons Namensnennung - Nicht-kommerziell - Keine Bearbeitung 4.0 International Lizenz. https://doi.org/10.1515/9783110703443-006 
Ile de France haben wir bereits in unserer Vorlesung über das ReiseSchreiben ${ }^{2}$ ausführlich und aus verschiedenen theoretischen Perspektivierungen behandelt, so dass wir uns stärker der - verzeihen Sie bitte das Wortspiel - Roman-tisierung dieses Stoffes durch den französischen Schriftsteller zuwenden können.

Bevor wir uns aber mit diesem literarhistorisch stark kanonisierten Roman näher beschäftigen, sollten wir zunächst - wie in all meinen Vorlesungen üblich einige Biographeme aus dem Leben Bernardin de Saint-Pierres in aller gebotenen Kürze behandeln, insbesondere dann, wenn diese für unsere Deutung der literarischen Phänomene von Bedeutung sind. Wer also war der Verfasser von Paul et Virginie, dieses kleinen Romans mit der großen und langanhaltenden Wirkung?

Jacques-Henri Bernardin de Saint-Pierre wurde am 19. Januar 1737 in der französischen Hafenstadt Le Havre geboren und verstarb am 21. Januar 1814 in der Nähe von Paris. Es gibt eine kleine Episode in seiner frühen Jugend, die ein bezeichnendes Licht auf ihn wirft. Denn er schifft sich 1749 unter dem Einfluss seiner Lektüre von Robinson Crusoe im Alter von zwölf Jahren nach Martinique ein, wobei ihm wohl sein Onkel mitgenommen hatte, der Kapitän war. Doch da er die einsame Insel auf den Antillen nicht fand, die er sich erträumte, soll er angewidert nach Frankreich zurückgekehrt sein. Schon der junge Mann steckt voller Träume, die zunächst einmal nicht in Erfüllung gingen.

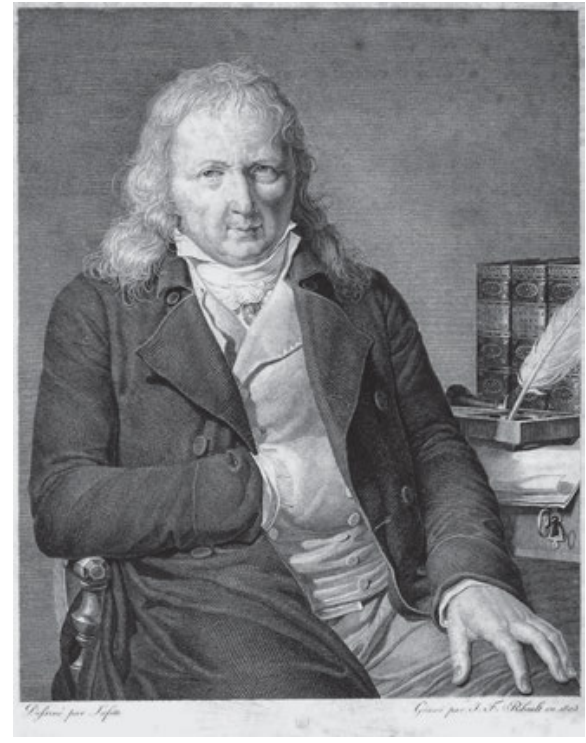

Abb. 10: Jacques-Henri Bernardin de SaintPierre (Le Havre, 1737 - Éragny bei Paris, 1814).

2 Vgl. Ette, Ottmar: ReiseSchreiben (2020). 
Nach seiner Ausbildung zwischen 1750 und 1756 an einer Jesuitenschule in Caen und dem Ende seiner Schulzeit am Collège de Rouen, wo er einen Preis in Mathematik erhält, tritt er in die Ecole Nationale des Ponts et Chaussées ein, wo er Straßen- und Brückenbau studiert und 1759 mit einem „Brevet d’ingénieur militaire“ abschließt. Als Ingenieur tritt er in die französische Armee ein, muss sie aber bereits 1762, mitten im Siebenjährigen Krieg, wegen Disziplinlosigkeit und seiner ,komplizierten“ Persönlichkeit wieder verlassen. Noch 1761 war er als Ingenieur auf die Insel Malta geschickt worden, scheitert in seiner Mission und Aufgabenstellung aber auch dort und kehrt enttäuscht nach Frankreich zurück. Eine schwierige Zeit mit Reisen nach Holland und Deutschland, nach Polen und Russland, wo er der Zarin Katharina II. vorgestellt wird, schließt sich an. Es sollte nicht die einzige schwierige Periode in seinem Leben bleiben. All seine Träumereien und nebulösen Vorhaben scheitern ebenso wie diverse amouröse Abenteuer. Bernardin de Saint-Pierre hält sich mit Gelegenheitsarbeiten über Wasser.

1767 reist er im französischen Auftrag nach Madagaskar, weigert sich aber, dort an Land zu gehen und setzt seine Reise bis zur Ile de France fort, wo er bis November 1770 als „Officier hors cadre“ und als „Surnuméraire“ lebt. Mit der Frau des Insel-Intendanten Poivre hat er eine unglückliche Liebelei. Er verwickelt sich in unsaubere koloniale Geschäfte, wird aber zum Kritiker des Kolonialismus und kehrt 1770 als solcher aus den Regionen des Indischen Ozeans wieder nach Frankreich zurück. Es folgt der schwierige Versuch, wieder in Frankreich Fuß zu fassen.

Dort scheitern zwar seine Bemühungen, Kontakte mit den Enzyklopädisten rund um Denis Diderot aufzunehmen, doch entsteht ein inniger Kontakt mit JeanJacques Rousseau, den er über alles bewundert und zu dessen Jünger er wird. Noch in Paul et Virginie finden sich zahlreiche Zeichen dieser Verehrung für den Genfer Philosophen. Sein 1773 erschienener Reisebericht Voyage à l'Ile de France ist auch heute noch überaus spannend zu lesen, doch findet er bei der zeitgenössischen Leserschaft nur wenig Anklang. Zu allem Überfluss kommt es auch noch zu einem Prozess mit dem Verleger: Für den nicht mehr ganz jungen Autor sind es wiederum schwierige Jahre, welche von vielfältigen Auseinandersetzungen und gesundheitlichen Problemen geprägt werden. Am Rande der Armut, von seinen Neurosen verfolgt und stark vereinsamt arbeitet er an seinen Etudes de la Nature. Rousseaus Tod scheint ihn sehr angegriffen zu haben. Doch diese Naturstudien läuten in seinem Leben die Wende ein.

Im Dezember 1784 erscheinen die in großer Einsamkeit entstandenen Etudes in drei Bänden, wobei Saint-Pierre L'Arcadie sowie Paul et Virginie vom Gesamttext abrennt, da sie bei einer Lektüre im kleinen Kreise keinerlei Erfolg hatten. Nach dieser negativen Erfahrung, so heißt es, habe der Autor sein Manuskript 
sogar verbrennen wollen. Erst der dritten Ausgabe seiner erfolgreichen Etudes, deren spekulatives Naturverständnis durchaus den Zeitgeist einer aufgeklärten Leserschaft traf, hängt Bernardin de Saint-Pierre 1788 eher widerstrebend seinen kurzen Roman Paul et Virginie an, der zu seiner Überraschung von Beginn an auf sehr positive Aufnahme stößt.

Bereits im folgenden Revolutionsjahr 1789 publiziert er eine eigenständige Ausgabe des handlichen Romans, der von nun an seinen Siegeszug beginnt: Es folgt eine Vielzahl von Ausgaben, illustrierten Editionen, literarischen Übersetzungen und Dramatisierungen, die Bernardin de Saint-Pierre plötzlich zu einem vom Lesepublikum hochverehrten Schriftsteller machen. Besonders das weibliche Publikum war höchst angetan: Saint-Pierre überschwemmt eine Flut von Briefen und Heiratsangeboten, die der nun umschwärmte Autor freilich ablehnt. Seit der ersten Publikation der Etudes de la Nature hatte sich Bernardins Los gewendet: Schnell wird der vielfach gescheiterte und verarmte Autor zu einem mit Ehren überhäuften Schriftsteller, der sich auch finanziell um seine Zukunft keinerlei Sorgen mehr machen muss. Selbst seiner hochspekulativen, aber literarisch interessanten Naturphilosophie blieb der zeitweilige wissenschaftliche Erfolg nicht versagt.

Der Erfolgsautor engagiert sich tendenziell für die Französische Revolution und beginnt bereits 1790 mit der Abfassung seiner Harmonies de la Nature, an denen er bis zu seinem Lebensende arbeiten sollte. Wissenschaftliche Erfolge stellen sich ein: Er wird 1792 zum Intendant des Jardin des Plantes und des Cabinet d'Histoire naturelle ernannt, womit er wissenschaftlich arriviert ist und über ein auskömmliches Einkommen verfügt. Noch im September 1792 wird er in Frankreich in die „Convention“ gewählt. Im Alter von siebenundfünfzig Jahren heiratet er die zwanzigjährige Tochter seines Druckers und Verlegers: Nach einem jahrzehntelangen Scheitern scheinen all seine Probleme und Sorgen wie weggeblasen. 1794 kommt seine erste Tochter auf die Welt, die selbstverständlich den Namen Virginie erhält, so wie der zweitgeborene Sohn auf den Namen Paul hören wird. Der Kreis seines Lebens schließt sich auf glückliche Weise.

Bernardin de Saint-Pierre wird zum Mitglied des „Institut“ und damit der höchsten wissenschaftlichen Institution im damaligen Frankreich. Nach dem frühen Tod seiner jungen Frau heiratet er noch einmal eine Zwanzigjährige. Eine Liebesbeziehung, die glücklich wird. Glücklich ist er auch in seinen Beziehungen zu Napoleon: Das Empire zeichnet den Schriftsteller und Naturphilosophen wiederholt aus: 1806 wird er in die Légion d'honneur aufgenommen. 1807 avanciert er zum Präsidenten der Académie Française, der Akademie der ,Unsterblichen“: Der einstmals gescheiterte Autor hat die höchsten Höhen erklommen. Da spielt es keine Rolle, dass seine späten Schriften nur noch geringen Erfolg haben: 
Er besorgt eine Luxusausgabe nach der anderen für Paul et Virginie. Erst nach seinem Tode werden seine Harmonies de la Nature erscheinen, an denen er bis zu seinem Ende feilt, deren Erfolg aber bei weitem nicht an denjenigen seiner Etudes de la Nature heranreicht. Doch für die Nachwelt wird der kurz nach seinem siebenundsiebzigsten Geburtstag im Jahr 1814 Verstorbene stets der Verfasser von Paul et Virginie bleiben.

So viel Biographisches mag einstweilen genügen; doch springen wir noch einmal in der Biographie zurück! Denn im Alter von sechsunddreißig Jahren veröffentlichte Bernardin de Saint-Pierre seine Voyage à l'Ile de France, die auf seine bereits erwähnte Reise nach Mauritius aus den Jahren 1768 bis 1770 zurückging. Der Reisebericht erschien zu einem Zeitpunkt, als sich sein Verfasser noch in keiner Weise als Schriftsteller profiliert hatte. Die Publikation war - wie bereits betont - ein Flop, wie man heute sagen würde. Bernardin de Saint-Pierres Aufenthalt auf der französischen Kolonialinsel dauerte insgesamt zwei Jahre und vier Monate: Zeit genug, um die Insel im Indischen Ozean gut kennen zu lernen. Diese war vor ihrer Kolonisierung durch die Europäer unbewohnt gewesen und hatte unter der kolonialen Herrschaft Portugals (1505-1598), der Niederlande (15981710) und Frankreichs (1715-1810) gestanden, bevor die Briten sie von 1810 bis 1968 übernahmen und danach in die Unabhängigkeit entließen.

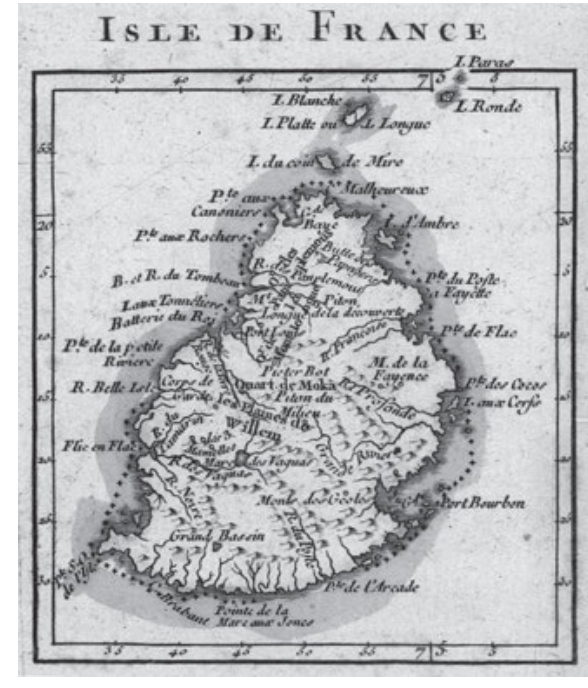

Abb. 11: Karte der Insel Mauritius von Rigobert Bonne, 1791.

Die Sichtweise der Insel Mauritius, die uns Bernardin de Saint-Pierre in seinem Reisebericht darbietet, hat nichts von einem Irdischen Paradies. Der Text präsentiere sich - wie Yves Bénot einmal festhielt - wie eine Art Anti-Reisebericht und steckt in der Tat voller Ausfälle gegen das Kolonialregime und die Sklave- 
rei. ${ }^{3}$ Freilich sei er durchaus dem Geschmack seiner Zeit nachgekommen, sei damals doch jede Reisebeschreibung eine Reise in das Wunderbare, in das „merveilleux“ gewesen. Doch war es keinesfalls bedeutungslos, dass Bernardin de Saint-Pierre am Ende seines Berichts einen Abschied vom Reisen einschob. Denn in der Tat sollte er für den Rest seines Lebens dem Reisen endgültig Lebewohl sagen - vom Reisen in der Literatur einmal abgesehen.

Ich möchte Ihnen gerne diese Passage zu Gehör bringen; es ist ein Zitat, in dem schon ein wenig Claude Lévi-Strauss’ „La fin des voyages“ anklingt, das von uns in einer früheren Vorlesung ${ }^{4}$ ausführlich analysierte Auftaktkapitel der Tristes Tropiques. Letzteres beschwor ebenfalls ein Ende der Reisen, mit dem auch die europäische Wissenschaft an die von der Moderne selbst gezogene Grenze intrinsischer Widersprüche stieß:

Von allen Landstrichen würde ich jene meines Landes vorziehen, nicht weil sie schön sind, sondern weil ich dort aufgewachsen bin. Es haftet am Geburtsort ein verborgener Reiz, ich weiß nicht was an Zärtlichem, das kein Vermögen zu geben vermöchte und das kein Land zurückgeben kann. Wohin sind die Spiele unserer frühen Kindheit, diese so vollen Tage ohne Voraussicht und ohne Bitterkeit? Das Fangen eines Vogels erfüllte mich mit tiefer Freude. [...] doch das Leben ist eine nur kurze Reise und das Alter des Menschen nichts als ein rascher Tag. Ich will die Gewitter vergessen, um mich nur mehr an die Wohltaten zu erinnern, an die Tugenden und die Konstanz meiner Freunde. Vielleicht bewahrt diese Schrift ihre Namen auf und lässt sie meine Dankbarkeit noch überleben! Vielleicht werden sie bis zu Euch reichen, ihr guten Holländer vom Kap! Für Dich, den unglücklichen Schwarzen, der auf den Felsen von Mauritius weint, wenn meine Hand, die Deine Tränen nicht trocknen kann, Deinem Tyrannen Bedauern und Reue einzuflößen vermag, so habe ich nichts mehr zu erbitten von den beiden Indien, denn ich habe dort ein Vermögen gemacht. ${ }^{5}$

Diese rhetorisch durchgefeilte Passage ist gleich in mehrfacher Hinsicht für uns höchst aufschlussreich. Gewiss nimmt sie eine Reihe klassischer Topoi auf, die ein bei den Schriftstellern der Antike durchaus belesener französischer Autor für seine in der Regel gleichermaßen gebildete Leserschaft aufzubieten verstand: vom Topos des Lebens als einer kurzen Reise bis hin zum berühmten „ubi sunt“, zum Topos der verlorenen Tage der Kindheit. Es handelt sich um die Suche nach der verlorenen Zeit, auf die sich der Schriftsteller immer wieder begeben kann, ja vielleicht sogar begeben muss. Wo also sind die glücklicheren Tage hin?

3 Vgl. Bénot, Yves: Introduction. In: Saint-Pierre, Bernardin de: Voyage à l'île de France. Un officier du Roi à l'île Maurice, 1768-1770. Introduction et notes d'Yves Bénot. Paris: La Découverte - Maspéro 1983, S. 7-22.

4 Vgl. Ette, Ottmar: ReiseSchreiben, S. 571-581.

5 Saint-Pierre, Bernardin de: Voyage à l'île de France, S. 258. 
Wir sind weit entfernt von einer paradieshaften Darstellung der Kolonialgebiete, endet doch der gesamte Text mit einer impliziten, aber doch unverkennbaren Verurteilung nicht allein des Kolonialismus, sondern vor allem der Sklaverei. Dieses Ausbeutungssystem wurde schon wenige Jahre später durch den Nationalkonvent der Französischen Revolution am 11. Februar 1794 abgeschafft, nicht zuletzt auf Grund des öffentlichen Drucks und des Gewichts der „opinion publique“, welche von der Société des Amis des Noirs, der Gesellschaft der Freunde der Schwarzen, ausgingen.

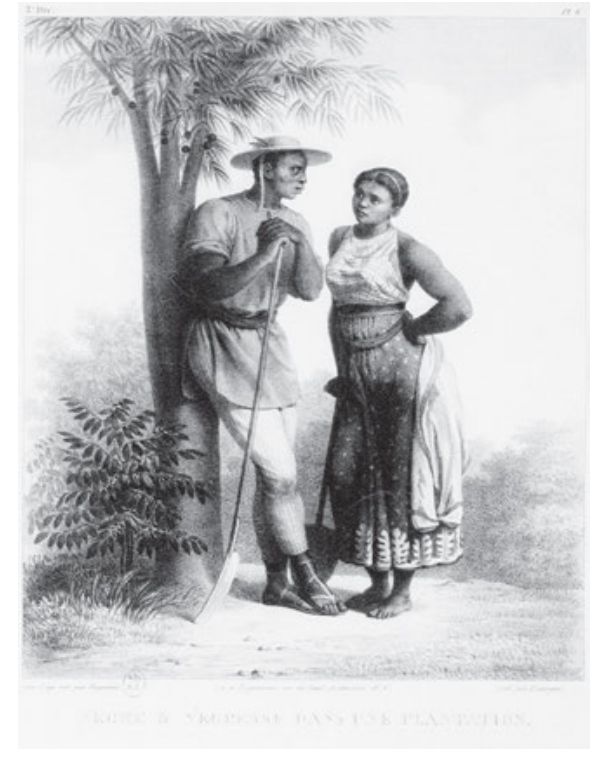

Abb. 12: „Nègre et négresse dans une plantation“, Lithografie von Johann Moritz Rugendas, 1835.

Zugleich wird dann im Übrigen ein weiterer Gemeinplatz nicht nur verwendet, sondern umgedreht, nämlich jener, dass man in die beiden Indien - in diesem Falle in die „Indes orientales“ - nur gehe, um dort reich zu werden, „pour faire fortune“. Bernardin de Saint-Pierre aber endet elegant mit einer Wendung und Widmung an die schwarze, nach Mauritius verschleppte Bevölkerung, die aus ihrem tyrannischen Los noch immer nicht entlassen sei. Mit dieser Wendung versucht er, seiner Reise und seinem Schreiben einen anderen Sinn für Reichtum abzugewinnen, den Reichtum der Freiheit und des Lebens, und diesen trotzig dem schnöden Mammon entgegenzustellen.

Fügen wir hier gleich hinzu, dass Bernardin de Saint-Pierres Einsatz für die Schwarzen durchaus seine Grenzen hatte, gibt es doch unzählige Stellen im Reisebericht und anderen seiner Schriften, die deutlich pejorative Wertungen über sie beinhalten und von den üblichen europäischen Vorurteilen geprägt sind. Über- 
dies - so fügte Yves Bénot in der zitierten Studie hinzu - bedeute Anti-Esklavismus nicht unbedingt Anti-Kolonialismus, wie überhaupt ein Gutteil der Debatte, ob die schwarzen Sklaven freigelassen werden sollten, auch unter dem Gesichtspunkt diskutiert wurde, gerade dadurch die Kolonien stabiler und sicherer, wenn auch zugleich humaner zu machen. Die Haltung des französischen Reisenden und Schriftstellers war in dieser Frage durchaus widersprüchlich. Seine bisweilen barsche Kritik am Kolonialismus ist durchaus nicht mit einer Ablehnung des kolonialen Ausbeutersystems gleichzusetzen.

Besonders bedeutsam aber ist an dieser Stelle die Tatsache, dass den weit entfernten Gebieten nun die eigene Landschaft entgegengestellt wird, die wir in diesem Zusammenhang sehr wohl als eine Landschaft der Theorie bezeichnen dürfen. ${ }^{6}$ Es geht um die Landschaften Europas, mehr noch: um die der eigenen Kindheit, und zwar nicht wegen ihrer Schönheit - und dies ist wichtig -, sondern weil sie die Heimat des Ich, des schreibenden Ich waren und sind. Es sind die Orte, an denen das Ich einst aufwuchs, an denen es seine kindlichen Freuden und Freundschaften erlebte. Denn dieses Ich legitimiert die vorrangige Beschäftigung mit dieser Landschaft: Erst aus der Perspektive einer zurückliegenden Geschichte, die sich bis in die Gegenwart des schreibenden Ich verlängern lässt, erhält diese Landschaft die Fähigkeit und die Berechtigung, zu einer literarischen Landschaft zu werden, welche der kolonialen Landschaft der Insel Mauritius gegenübergestellt wird.

Ein weiteres Element, das mir in dieser wohlkalkuliert verfassten Passage wichtig erscheint, ist jene Formel des „Je ne sais quoi“, in der Erich Köhler ein Charakteristikum jenes irrationalen Rests innerhalb einer zunehmend durchrationalisierten Welt verstand, der zu einem gewichtigen Ausgangs- und Bezugspunkt der Romantik werden sollte. ${ }^{7}$ Das „Je ne sais quoi“ als Merkzeichen der Romantik zeigt jene Bestände auf, die sich nicht in die rationale Logik der Aufklärung auflösen lassen, sondern gerade zum Ausgangspunkt der eigenen modernen Subjektivität in ihrer Differenzqualität werden. Wir haben es hier mit dem wahrlich interessanten Ende eines Textes zu tun, der zum Zeitpunkt seines Erscheinens noch wenige Leser fand und keineswegs hätte erwarten lassen, dass aus der Feder desselben Autors dereinst ein weiterer Text entstehen würde, der als einer der wichtigsten Fiktionen des „Préromantisme“ und des literarischen Exotismus aufgefasst werden sollte.

6 Vgl. zu diesem Begriff Ette, Ottmar: Roland Barthes. Landschaften der Theorie. Konstanz: Konstanz University Press 2013.

7 Vgl. hierzu Köhler, Erich: „Je ne sais quoi“. Ein Kapitel aus der Begriffsgeschichte des Unbegreiflichen. In ders.: Esprit und arkadische Freiheit. Aufsätze aus der Welt der Romania. Frankfurt am Main: Athenäum Verlag 1966, S. $230 \mathrm{ff}$. 
Am Ende einer Reise in die kolonialfranzösische Welt der Insel Mauritius steht in einem deutlich autobiographischen Duktus das Ende der Reise (und der Lebensreise) überhaupt, ein Bewusstwerdungsprozess, der durch die kreisförmige Reisebewegung räumlich vorgeführt beziehungsweise als Bewegungsfigur spatialisiert wird und in einer Art Mise en abyme innerhalb des Textes selbst in der Umrundung der Insel zu Fuß gleichsam vorweggenommen wird. Zugleich enthält der Reisebericht Voyage à l'Ile de France alle literarischen, sozialen und landschaftlichen Ingredienzien, die dem französischen Autor später für den Entwurf seiner auf Mauritius angesiedelten Romanhandlung dienen werden.

Der Voyage à l'Ile de France ist zweifellos ein gutes Beispiel für einen Reisebericht des 18. Jahrhunderts, der in diesem Fall eine Abfolge von Briefen enthält und von daher selbstverständlich - wie stets in der Hybridgattung des Reiseberichts unterschiedliche literarische Genres und Formen der Subjektkonstituierung miteinander in Verbindung bringt. Die literarisch in den Reisebericht eingefügten Briefe enthalten innerhalb ihrer Texte noch zusätzliche Datierungen, so dass sie sich über das Epistolare hinaus zugleich auch als Reisejournale, als Reisetagebücher erweisen und ansehen lassen.

Interessanterweise gliedert sich die Reise nach Mauritius ihrerseits wiederum in eine Abfolge verschiedener Reisen innerhalb dieser Gesamtreise, so dass eine recht komplexe Figur des Zusammenspiels reiseliterarischer Einzeltexte erscheint. Durch die Briefform erhält freilich - gegenüber einem traditionellen Reisebericht - die Frage autobiographischer Modellierung von Subjektivität verstärkte literarische Ausdrucksmöglichkeiten. Dies zeigt sich gerade auch bei einem Abschnitt der Reise, in deren Fortgang das Ich seinen Reiseführer verloren hat und auf sich alleine gestellt seinen Plan trotz alledem in die Tat umsetzt, die Montagne des Trois Mamelles - welch schöner Name! - zu besteigen und von dort aus, auch wenn es längst Nacht geworden ist, einen Blick auf die gesamte Insellandschaft zu werfen. Schauen wir uns diese Passage in einem kurzen Auszug an:

Ich traf nun meine Entscheidung. Ich beschloss, durch die Wälder aufzusteigen, auch wenn ich keinerlei Art von Weg entdecken konnte. So stieg ich nun die Felsen hinauf, wobei ich mich bisweilen an den Bäumen festhielt, bisweilen von meinem Schwarzen gestützt wurde, der hinter mir ging. Ich war noch keine halbe Stunde gelaufen, als die Nacht hereinbrach: So besaß ich nun keinen anderen Führer mehr als den Abhang des Gebirges selbst. Der Wind war eingeschlafen und die Luft war noch heiß; ich vermag Ihnen kaum zu sagen, unter welchem Durst und unter welcher Müdigkeit ich litt. Mehrmals legte ich mich hin und war entschlossen, einfach an Ort und Stelle zu bleiben. Nach unglaublichen Mühsalen bemerkte ich endlich, dass ich ständig aufwärts ging; bald darauf spürte ich im Gesicht die Frische eines Windes aus Südosten, und ich sah von weitem Feuer in der Landschaft. Die Seite, die ich hinter mir ließ, war in eine tiefe Dunkelheit getaucht.

Schließlich stieg ich hinab, indem ich mich oftmals ungewollt hinunterrutschen ließ. Ich orientierte mich am Geräusch eines Baches, wo ich endlich völlig zerschlagen ankam. Obwohl 
ich schweißnass war, trank ich nach Belieben, und da ich unter meinen Händen Gras spürte, fand ich zu meinem größten Glücke, dass es Kresse war, von dem ich mehrere Handvoll verschlang. Ich setzte meinen Marsch in Richtung des Feuers fort, das ich sah, wobei ich Vorsicht walten ließ und meine Pistolen aus der Angst, es könnte sich um eine Versammlung geflüchteter schwarzer Marrons handeln, entsichert hatte: Ich stieß auf eine Lichtung, auf der mehrere Baumstämme im Feuer lagen. Keinen Menschen fand ich dort vor. ${ }^{8}$

Diese Passage mag belegen, was für ein begabter Schriftsteller Bernardin de SaintPierre bereits zu jenem Zeitpunkt war und wie geschickt er einzelne Episoden seiner Reise literarisch herauszuarbeiten verstand. Das Ich wurde von seinem Führer verlassen und muss sich inmitten der Dunkelheit selbst zurechtfinden, freilich begleitet von einem schwarzen Sklaven, von dem wir eher beiläufig, geradezu zufällig erfahren. Dieser Sklave, der hinter seinem Herren geht, stützt das Ich so, wie sich dieses auch an Bäumen festhält: Der Schwarze ist in dieser Passage nicht mehr als ein Gegenstand der Natur, welcher dem reisenden, die Gipfel erklimmenden Ich zu Hilfe kommt.

Gleichwohl findet sich dieses Ich verloren inmitten einer Natur wieder, welche vom Menschen nicht beherrscht wird. Nicht Wege, also öffentliche Infrastruktur und kulturelle Institutionen, sondern Abhänge und damit die Natur selbst geben den weiteren Weg des Subjekts zur Spitze des Berges vor, zum „Gebirge der drei Brüste“. Im Grunde erweist sich diese Szenerie als Prüfung, deren Qualen und Peinigungen das Ich durchzustehen hat, um eine letztlich nur sehr schwer nachvollziehbare Handlung zu Ende zu bringen: die Besteigung eines Berges bei Nacht, in völliger Dunkelheit, und das Erreichen einer Bergspitze, von der aus dann freilich einige Lichter in der Ebene gesehen werden können. Es handelt sich um eine Prüfung, gerade weil ihr Gegenstand wie ihre Zielsetzung im Grunde absurd sind. Und kein Zweifel: Das Ich hat diese Prüfung bestanden!

Dunkelheit, Orientierungslosigkeit, unerträgliches Klima, Wegelosigkeit, Führerlosigkeit, enorme körperliche Anstrengung und vieles mehr: All dies sind Grenzerfahrungen des Subjekts, wir dürfen hinzusetzen: eines modernen Subjekts, die bis zur gleichsam tierischen Nahrungsaufnahme in Form von am Bach wachsender Kresse gehen. Doch all diese Erprobungen des Ich werden am guten Ausgang mit einem Glücksgefühl belohnt, bevor die Absurdität des eingeschlagenen Weges noch einmal aufscheint.

In dieser Passage finden sich kulturelle Erfahrungsmuster des modernen Menschen vorgeprägt, der eigentlich grundlos die Herausforderung sucht, wobei hier in einem bestenfalls präromantischen Sinne die Natur selbst einen ambi-

8 Saint-Pierre, Bernardin de: Voyage à l'île de France, S. $149 \mathrm{f}$. 
valenten Status besitzt. Denn einerseits ist sie ein Ort der Herausforderung, der Bedrohung und auch die Lebensbedrohung selbst; andererseits erlaubt sie dem Subjekt eine Selbstvergewisserung, die in der eigenen Umgebung, im alltäglichen Lebensablauf, in dieser radikalen Daseinserfahrung nicht möglich wäre.

Mir scheint, dass gerade diese buchstäblich auf die Spitze getriebene Szenerie, die eigentlich nur durch das Subjekt motiviert und auch nur vom Subjekt durchgeführt wird, auf sehr anschauliche und konzentrierte Weise ebenfalls „La fin des voyages“ schon andeutet, nicht aber die Grenzerfahrung des Ich in der äußersten Erprobung seiner Fähigkeiten. Zweifellos werden wir an dieser Stelle einfügen müssen, dass ein Schwarzer das Ich begleitete und ihm als Stütze diente; doch als Sklave verschwimmt dieses namenlose Subjekt in der Nacht und muss, ebenso wie die hilfreichen Bäume, nicht nochmals erwähnt werden. Dass dieser schwarze Sklave die Eskapaden seines Herrn und Meisters klaglos mitmachen muss, findet keine Berücksichtigung. Sehr wohl werden jedoch die Aktivitäten des weißen Subjekts beschrieben, welche jedoch nicht mehr - wie etwa im Bereich der Entdeckungsreise oder der Forschungsreise - einem bestimmten zu erreichenden Ziel untergeordnet werden. In der hier geschilderten Szenerie ist das eigentliche Ziel das Subjekt, das Ich des Reisenden und Schriftstellers, das sich ohne eigentlichen Grund und Anlass zu erproben sucht, bis an die eigenen Grenzen geht und - wie ein Bungee-Springer seine Angst vor dem eigenen Mut überwindend - seine selbstauferlegte Prüfung besteht. Ich greife zum Vergleich wahllos irgendeine Werbung für Bungee-Springen aus dem Internet auf: „Dein Puls schlägt schneller. Erlebe den freien Fall. Einzigartige Erlebnisse. Geprüfte Erlebnisse.“ Wir befinden uns in diesem noch präromantischen Setting auf den Spuren des modernen Subjekts und bemerken, wie nahe uns dies alles noch heute ist.

Bei Bernardin de Saint-Pierre lässt sich sehr eindrücklich der jahrzehntelange Weg vom noch nicht schreibenden Ingenieur und Militär über eine lange Phase des Verfassens eines Reiseberichts und spekulativer Naturstudien in seinen Etudes de la Nature hin zur Arbeit an romanesker Fiktion, an der Ausarbeitung eines Romans beobachten, der ursprünglich am Ausgang des letzten Bandes seiner Naturstudien stehen sollte. Wir erleben so die Geburt des Romans aus dem Geiste des Studiums der Natur und können ermessen, welch große Bedeutung bei dieser Entwicklung der Natur und ihrer naturphilosophischen wie literarischen Darstellung zukommt. So mag es kein Zufall sein, dass Alexander von Humboldt lange Jahrzehnte danach noch immer begeistert von jenen Naturszenen berichtete, die er bei Bernardin de Saint-Pierre einst gelesen hatte und mit denen wir uns auf dem weiteren Weg unserer Vorlesung noch beschäftigen werden.

Bernardin de Saint-Pierres aufopferungsvolle und mühselige intratextuelle Arbeit am eigenen Text führt vom selbstgeführten Journal der Reise in den Indi- 
schen Ozean, schließlich zum Reisebericht und von diesem zu fiktionalen Briefen über die unternommene Reise, von wo aus im Grunde der Weg zur Niederschrift eines Romans nicht mehr sehr weit ist. Die Ankunft in der Literatur ist dabei nicht so linear, wie es diese verkürzte Darstellung des literarischen Entwicklungsganges vielleicht nahelegen könnte. Vergessen wir nicht, dass der französische Schriftsteller für diesen Weg lange Jahre einer mühseligen Existenz am Rande von Armut und gesellschaftlicher Ächtung benötigte! Auf ihm traten eine Reihe anderer, gattungstechnisch bedingter Elemente hinzu, die veränderte Erzählstrukturen und Darstellungsmuster schufen, die wir im Übrigen nun unverkennbar dem Vertreter des „Préromantisme“ und Wegbereiter der Romantik zuordnen können. Dass hierbei wiederum die Ambivalenz der Natur erscheinen musste, freilich in das Licht eines noch dramatischeren Kontrasts gestellt, werden wir sogleich erleben.

Paul et Virginie, der großartige kleine Roman von Bernardin de Saint-Pierre, ist zweifellos das große Lebenswerk des Franzosen. Er ist jener Text, der alle anderen aus der Feder des eigenwilligen Autors - seien es die Etudes de la Nature aus dem Jahr 1784, deren ursprüngliches ,Anhängsel` er wie besprochen war, seien es La Chaumière indienne von 1791 oder seine erst posthum veröffentlichten Harmonies de la Nature - im Verlauf einer langen Rezeptionsgeschichte in den Schatten stellte. Die erste von den Etudes unabhängige Publikation des Romans - wenn wir ihn denn so nennen wollen - fiel in das Jahr der Französischen Revolution, die Bernardin de Saint-Pierre, ein letztlich treuer Schüler Rousseaus, hoffnungsvoll begrüßte. Er bekleidete in ihr durchaus nicht unwichtige Posten, ohne es doch beim Erscheinen Napoleons zu versäumen, den sich verändernden neuen Machtverhältnissen gebührend Rechnung zu tragen und seinen gesellschaftlichen, wissenschaftlichen und nicht zuletzt literarischen Aufstieg zu vollenden.

„Histoire“ und „récit“, Story und Plot seines größten Publikumserfolgs sind schnell erzählt. Gestatten Sie zunächst jedoch einige Bemerkungen zur Art des „Plotting“. Der explizite Autor - natürlich nicht der reale Autor aus Fleisch und Blut - stößt auf der Ile-de-France, nicht allzu weit von der Hauptstadt Port-Louis entfernt, auf einen alten Mann, der inmitten von Ruinen in einer nachdenklichen, melancholischen Haltung sitzt. Dieser alte Mann wird nun gegenüber unserer expliziten Autorfigur und damit auch gegenüber dem Lesepublikum zum Erzähler jener Geschichte, die Paul et Virginie auf der Ebene der „histoire“, der Story bildet. Am Ende des Romans wird diese Erzählerfiktion wieder aufgenommen: Die Autorfigur erscheint noch ein letztes Mal und gemahnt an die Erzählsituation mit unserem alten Mann, der sich im Übrigen immer wieder in die unterschiedlichsten Szenen des Romans kommentierend einblendet. Wir haben es folglich mit einem erzähltechnisch gerahmten Text und dergestalt mit einer Aufteilung in eine Rahmen- und eine Binnenerzählung zu tun. 
Diesen so angeordneten Rahmen können wir erzähltechnisch noch weiter untersuchen. Denn die Erzählerfigur des alten Mannes ist zugleich intradiegetisch - sie ist Teil des Buches und wird als literarische Figur eingeführt - und homodiegetisch, das heißt, dass sie Anteil am Geschehen selbst hatte, von dem sie berichtet. Unter einer Diegese ist die ausgespannte Raum-Zeit-Struktur eines Erzähltextes zu verstehen, also Rahmen- und Binnenerzählung gemeinsam. Sie begreifen: Wir haben es mit zwei verschiedenen Zeitebenen zu tun, auf denen sie angeordnet ist! Der betagte Erzähler ist ja nun alt und blickt in die Vergangenheit zurück, aus der er uns berichtet. Die Zukunft der längst vergangenen Zeit ist eine vergangene Zukunft, die freilich in ihrer damaligen Zukunftsoffenheit erfahrbar und nacherlebbar wird. Insgesamt jedoch haben wir es mit einer recht einfachen, überschaubaren narrativen Grundstruktur zu tun, die dem Schriftsteller strukturell keine hohe Komplexität abverlangt und von der Leserschaft leicht nachzuvollziehen ist. Man könnte dies auch als leichte Lesbarkeit des Textes umschreiben.

Bevor ich Ihnen dies alles genau am Text vorführen kann, muss ich Ihnen zumindest einige weitere Teile der „histoire“ erzählen. Nun, auf der Insel Mauritius lebten einst mitten im Indischen Ozean die von ihrem Heimatland Frankreich und dessen Zivilisation - und hier kommen zivilisationskritische Aspekte mit ins Spiel - bitter enttäuschte Madame de la Tour mit ihrer hübschen Tochter Virginie. Sie wohnen mit der Madame eng befreundeten Marguerite und deren nicht weniger hübschem Sohn Paul und ihren wohlerzogenen, treuen und edlen schwarzen Sklaven zusammen. Diese Sklaven heißen Domingue - noch ist die Sklavenrevolution auf Saint-Domingue, dem späteren Haiti, nicht ausgebrochen und der Name dadurch noch nicht revolutionär kontaminiert - sowie Marie, was auf die christliche Erziehung und Legitimation der Sklaverei verweist. Sie leben in einfachen Verhältnissen, aber stets glücklich in einer perfekten Idylle, die ein Gegenbild darstellt zur französischen Gesellschaft am Ende des Ancien Régime. Die beiden Kinder Paul und Virginie wachsen zusammen auf und erfreuen sich des Lebens in einer natürlichen tropischen Umwelt, die mit all ihren für in Frankreich lebende Franzosen exotischen Reizen geschildert wird. $\mathrm{Zu}$ dieser quasinatürlichen Umwelt zählen selbstverständlich auch die edlen und stets mitfühlenden Sklaven.

Es kommt, wie es kommen muss: Die Kinder wachsen heran und verlieben sich zunehmend ineinander, ohne sich dies freilich eingestehen $\mathrm{zu}$ wollen. Der erste Teil der Geschichte ist rosafarben, der zweite dunkel gestaltet und auf die Scharnier- oder Trennstelle komme ich gleich zu sprechen. Wir durchleben das Aufwachsen der Kinder und sehen ihre entstehende Liebesbeziehung in einem exotischen und exotisierten Kontext: Sie leben ihr Leben in einer zwar sittenstrengen, aber gleichwohl atmosphärisch spürbaren Freiheit, die im ersten Teil geradezu utopische Züge annimmt und auf eine Konvivenz jenseits vermeint- 
licher Standesgrenzen hinausläuft. Entscheidend ist dabei die Vorstellung, dass ein solches Zusammenleben jenseits aller Grenzen, die eine kolonialistische und statische Standes-Gesellschaft des Ancien Régime errichtet hat, sehr wohl möglich sei. Literatur wird in diesem Zusammenhang zu einem Laboratorium des Zusammenlebenswissens, so wie es seit 1001 Nacht immer wieder experimentell erprobt wurde. ${ }^{9}$

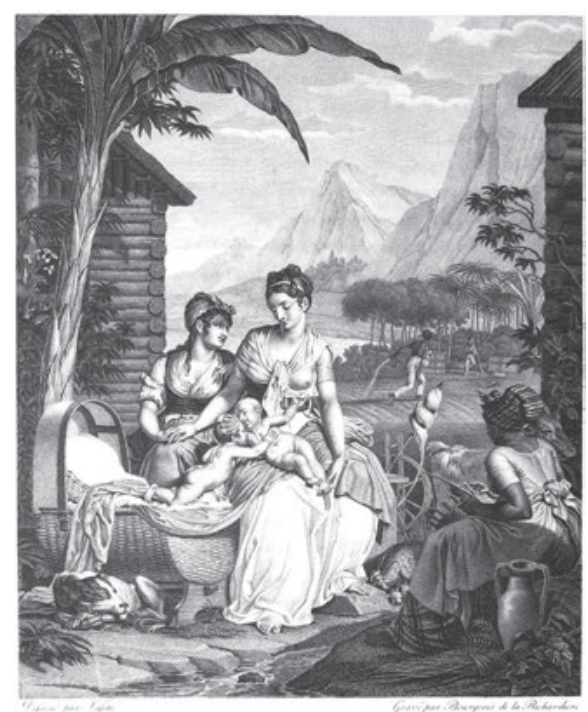

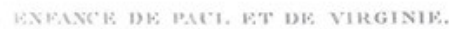

Abb. 13a: „Enfance de Paul et Virginie“, Abbildung aus Paul et Virginie, 1806.

Dann jedoch ereignet sich das Unglück: Und es kommt selbstverständlich aus Frankreich, also von weither. In Form eines Briefes einer Erbtante wird Madame de la Tour, im Gegensatz zu Marguerite von adliger Abkunft, aufgefordert, ihrer nunmehr fünfzehnjährigen Tochter Virginie, die längst in die Pubertät gekommen ist und natürlich zu einer unglaublich hübschen jungen Frau heranwächst, eine standesgemäße Ausbildung in Frankreich zu ermöglichen. Dafür wolle sie, die Erbtante, gerne alle finanziellen Mittel bereitstellen und auch die Überfahrt nach Frankreich bezahlen. Nach einigem anfänglichem Zögern wird der Plan angenommen - zur größten Verzweiflung der beiden Liebenden, die nun auseinandergeris-

9 Vgl. hierzu Ette, Ottmar: ZusammenLebensWissen. List, Last und Lust literarischer Konvivenz im globalen Maßstab (ÜberLebenswissen III). Berlin: Kulturverlag Kadmos 2010; sowie ders.: Konvivenz. Literatur und Leben nach dem Paradies. Berlin: Kulturverlag Kadmos 2012. 
sen werden. Die Idylle - oder wir müssten genauer sagen: die gesellschaftliche Utopie - endet abrupt.

Nun beginnt die zweite Hälfte des Romans, und wieder kommt es, wie es kommen muss: Virginie wird nach Frankreich gebracht, eine wirkliche Weltreise nicht nur in der damaligen Zeit, findet aber leider keinen Gefallen an der dortigen ständischen Zivilisation mit ihren gesellschaftlichen Gegensätzen, von deren Auswüchsen sie kritisch in ihren Briefen berichtet. Alles verstößt gegen die Gesetze der Natur, gegen die so natürlichen Sitten. Man könnte von einer Art Lettres persanes sprechen, nur diesmal mauritianisch-französischer Natur: Denn Virginie ist Französin und zugleich doch keine Französin, insofern sie in einer anderen Kultur aufgewachsen ist und so die französische Gesellschaft mit ihren Briefen wie bei Montesquieu gleichsam von außen beleuchtet und reflektiert.

Doch ganz so, wie Virginie sich nicht an die Sitten und Gewohnheiten Frankreichs anzupassen vermag, finden auch die französische Zivilisation und deren Vertreterinnen und Vertreter keinen Gefallen an ihr. Folglich wird sie von ihrer Tante enterbt und verlässt Frankreich wieder, zwar auf eine noch immer natürliche Weise wohlerzogen, aber sich gleichwohl auf die angestammte Heimat ihrer ,Neuen Welt' in den französischen Kolonien und auf ihren lieben Paul freuend. Alles wirkt, als könnte sich das Romangeschehen noch zu einem guten Ende fügen.

Aber das Schiff, das sie nach etwa zweijähriger Abwesenheit wieder zurück nach Mauritius bringen soll, kommt unmittelbar vor der Ankunft in einen schweren Sturm - der Autor Bernardin de Saint-Pierre hatte derartige Stürme selbst hautnah erlebt, aber überlebt und bereits in seinem Reisebericht beschrieben. Ja, Sie ahnen es schon: Dieses Glück sollte Virginie nicht beschieden sein, denn sie wird in diesem Sturm untergehen! Und dies nicht irgendwie, sondern recht spektakulär, wie wir gleich sehen werden: vor den Augen des verzweifelten Pauls und anderer Beobachter der grässlichen Szenerie. Es ist also das, was man in der Tradition von Lukrezens De rerum natura schlicht als einen Schiffbruch mit Zuschauer bezeichnen könnte, ein Motiv, mit dem sich der Philosoph Hans Blumenberg ausführlich auseinandergesetzt hat. ${ }^{10}$ Die unmittelbaren Folgen sind klar: Die einst so fröhliche Gemeinschaft überlebt das Unglück nicht lange und siecht sterbend dahin. Am Ende des Romans gemahnen nur noch einige wenige Reste an die Stätte des einstigen Glücks und bilden jenen geheimnisvollen und düsteren Ort, an dem der alte Mann seine Geschichte erzählt.

10 Vgl. Blumenberg, Hans: Schiffbruch mit Zuschauer. Paradigma einer Daseinsmetapher. Frankfurt am Main: Suhrkamp 1979. 
Sie mögen nun verwundert sein oder nicht, doch mit so einer Geschichte macht man Weltliteratur! Gleichzeitig füge ich hinzu: nicht damit allein. Denn der Roman hat es, wenn er auch allzu oft - freilich nie von seinen treuen Leserinnen und Lesern - unterschätzt wurde, wirklich in sich. Er ist in seinen Konstruktionsprinzipien recht einfach, aber sehr durchdacht und konsequent aufgebaut, eine wahre Freude für jeden Narratologen, der all seine Modelle bestätigt sieht. Paul et Virginie bildet in dieser Hinsicht sicherlich einen Vorzeigeroman.

In der bislang entfalteten Verbindung von „histoire“ und „récit“ möchte ich Ihnen die Nahtstelle etwas genauer zeigen, an der unter dem Licht des Kreuzes des Südens die Handlung kippt. Dies war übrigens eine Stelle, die Alexander von Humboldt ganz besonders bewunderte, war für ihn doch das Kreuz des Südens jene Konstellation, die stellvertretend für die von ihm - im doppelten Wortsinne heiß geliebten Tropen stand. Nicht umsonst war Paul et Virginie ein Roman, den er mit besonderer Zuneigung mit auf seine Reise dorthin nahm. Aber zurück zu jener Passage, in der die erste Hälfte des auf Mauritius angesiedelten Romans, also jene ,rosafarbene‘, in die zweite, düstere Hälfte übergeht! Passen Sie gut auf:

Ich sagte zu Paul: „Mein Freund, Ihre Schwester wird bleiben. Morgen sprechen wir darüber mit dem Gouverneur: Lassen Sie Ihre Familie sich erholen und verbringen Sie diese Nacht bei mir. Es ist spät, es ist Mitternacht: Das Kreuz des Südens steht gerade über dem Horizont."

Er ließ sich wortlos mitnehmen und stand, nach einer sehr unruhigen Nacht, gleich im Morgengrauen auf, um zu seiner Wohnung zurückzukehren.

„Aber wozu soll es gut sein, dass ich Ihnen noch länger den Verlauf dieser Geschichte erzähle? Es gibt im Leben des Menschen immer nur eine einzige angenehme Seite, die man kennen muss. Dem Erdball ähnlich, auf dem wir umherstreifen, ist unsere rasche Umdrehung nichts als ein Tag, und nur ein Teil dieses Tages kann das Licht empfangen, wobei der andere Teil der Finsternis ausgeliefert bleibt.“

„Mein Vater, sagte ich ihm, ich beschwöre Sie, führen Sie das, was Sie auf eine so berührende Art und Weise zu erzählen begonnen haben, zu seinem Ende. Die Bilder des Glücks gefallen uns, aber jene des Unglücks sind für uns lehrreich. So bitte ich Euch: Was wurde aus dem unglücklichen Paul?“

- „Das erste, was Paul sah, nachdem er nach Hause zurückgekehrt, war die Schwarze Marie, die auf einem Felsen sitzend zum offenen Meer hin schaute. Er rief ihr schon von weitem zu, als er sie sah: „Wo ist Virginie?“ Marie drehte ihrem jungen Herrn den Kopf zu und begann zu weinen. Paul war außer sich, kehrte auf der Stelle um und lief hinunter zum Hafen. Er erfuhr dort, dass Virginie sich im Morgengrauen eingeschifft hatte, dass ihr Schiff alsbald die Segel gesetzt hatte und dass man es schon nicht mehr sehe. Er ging wieder hinauf zur Wohnung, die er durchquerte, ohne noch mit jemandem zu sprechen." ${ }^{11}$

11 Saint-Pierre, Bernardin de: Paul et Virginie. Edition revue et augmentée d'une chronologie. Paris: Editions Garnier Frères 1964, S. 154 f. 
In dieser wunderbar durchkomponierten Passage, die uns zeigt, wie überzeugend Bernardin de Saint-Pierre konstruieren und schreiben konnte, laufen im Grunde alle wesentlichen Erzählfäden und Metaphorologien des gesamten Romans zusammen. Zunächst einmal können wir hier einen Wechsel zwischen den beiden Zeitebenen beziehungsweise Diegesen des Romans beobachten. Sind wir am Anfang noch auf der Ebene der erzählten Zeit, so wechseln wir rasch auf jene der Erzählzeit, in der der alte Mann dem vermeintlichen Autor des Textes, der „Ich“ sagt wie sein Erzähler im Dialog, die gesamte Geschichte unterbreitet und vorführt.

Hübsch und überzeugend ist dabei, dass er uns auch noch vorführt, dass die Begriffe „récit“ und „histoire“ im Französischen keineswegs theoretische, ja völlig abstruse Begriffe sind, die kein Erzähler in den Mund nehmen würde, sondern sich bereits im 18. Jahrhundert dazu eigneten, dem Adressaten einer Erzählung und damit der verehrten Leserschaft genauer zu erklären, wie man einen vernünftigen Erzähltext schreibt. „Récit“ ist also die Anordnung jener narrativen Elemente, welche die „histoire“ als die Gesamtheit aller Erzählelemente und Erzählmomente eines Textes in eine lineare Sequenz einrückt. Wie erzähle ich also? Indem ich mir überlege, wie ich die einzelnen Teilsequenzen zu einer Gesamtsequenz anordne, wie ich also die Bestandteile der „histoire“, der Geschichte, die ich erzählen möchte, in einen „récit“ integriere und Stück für Stück aufeinander folgen lasse.

Halten wir an dieser Stelle fest: Literatur ist eine Kunst der Zeit, ganz so wie die Musik, und nicht so sehr eine Kunst des Raumes wie etwa Malerei oder Bildhauerei! Sie sehen zugleich: Unser Erzähler ist ein Teil der hier repräsentierten Geschichte ebenso wie jenes Ich, dem alles erzählt wird. So griff er selbst in die Geschichte ein, indem er etwa Paul dazu bewegte, in der Nacht, an deren Ende Virginie nach Frankreich aufbrechen musste, nicht zuhause zu sein, sondern bei ihm zu nächtigen, so dass der junge Mann seine geliebte Virginie nicht wiedersehen wird und ihr noch nicht einmal Adieu sagen konnte. Kein Wunder also, dass er mit niemandem mehr sprechen möchte.

Beide Ichs sind Romanfiguren, genauer: Sie sind auf der Ebene der Erzählzeit Figuren des Romans, gehören also von innen her zu diesem erzählerischen Rahmen, sind daher intradiegetisch im Sinne Gérard Genettes. ${ }^{12}$ Mit anderen Worten: Sie gehören folglich zur Diegese, der raumzeitlichen Gesamtheit dieser erzähltechnisch zu untersuchenden Ebene des Romans. Der alte Mann spricht, wie wir zugleich sehen, in seiner Erinnerung mit dem jungen Paul: Er ist also auch

12 Vgl. zu dieser erzähltechnischen Begrifflichkeit Genette, Gérard: Nouveau discours du récit. Paris: Seuil 1983. 
eine Figur auf der weiter zurückliegenden Ebene der erzählten Zeit, was Genette als homodiegetisch bezeichnet.

Jene Figur, die ebenfalls „Ich“ sagt und die ich als expliziten Autor bezeichnet habe, ist hingegen keine Figur auf Ebene dieser Diegese der erzählten Zeit, sondern nur der romanesken Rahmenerzählung. Daher dürfen wir sie nicht als homodiegetisch, sondern müssen sie als heterodiegetisch bezeichnen. Sie muss vom alten Mann ja erst in Kenntnis der gesamten Geschichte gesetzt werden, was überhaupt die Motivation für den gesamten Erzählvorgang - die „narration“ also - ist. Sie sehen: Die Dinge liegen einfach und sind doch zugleich nicht ganz trivial! Aber ich darf Sie trösten: Das narratologische Nachvollziehen komplexer Geschichten macht bisweilen selbst ausgebufften Narratologen Mühe, auch wenn wir die erzählerischen Zusammenhänge geradezu instinktiv - weil wir all dies in einem langen Lernprozess wie die Muttermilch eingesogen haben - verstehen und nachvollziehen können. Es bereitet auch Vergnügen, so wie jede Form des Verstehens Vergnügen und Freude bereitet. Nicht umsonst bezeichnete der Freiburger Romanist Hugo Friedrich die Philologie als eine „genießende“ Wissenschaft. ${ }^{13}$

Wir haben bereits gesehen, dass genau dann der Übergang von der Binnenerzählung zur Rahmenerzählung vollzogen wird, also von der erzählten Zeit zur Erzählzeit, wenn im Text tatsächlich von der Zeit die Rede ist: Wir werfen einen Blick auf die Uhrzeiger des Kreuzes des Südens, so dass die Natur selbst hier die Zeitangabe einblendet und uns wie allen Romanfiguren sagt, dass nun Mitternacht sei. Denn diese Konstellation pflegt, sich wie die Zeiger an einer Uhr im Verlaufe einer Sternennacht zu drehen.

So beginnt also ein neuer Tag, und zwar kein guter! Die Geschichte selbst wäre darum um ein Haar stehengeblieben. Denn angesichts der Ereignisse, von welchen er nun berichten muss, überlegt es sich der Erzähler noch einmal, ob er wirklich derartig grausame Dinge vorstellen müsse: Wo Licht ist, sei auch Schatten, und wo Glück ist, gebe es auch Unglück.

An dieser Stelle greift unser expliziter „Auctor“ ein - kein Wunder, er hätte ja sonst nichts zu gestalten gehabt - und gibt seinen Fundus an von der abendlän-

13 Vgl. hierzu Friedrich, Hugo: Dichtung und die Methoden ihrer Deutung. In: Die Albert-Ludwigs-Universität Freiburg 1457-1957. Die Festvorträge bei der Jubiläumsfeier. Freiburg i.Br.: Hans Ferdinand Schulz 1957, Bd. 2, S. 95-110; zitiert nach Friedrich, Hugo: Dichtung und die Methoden ihrer Deutung. In: Wais, Kurt (Hg.): Interpretationen französischer Gedichte. Darmstadt: Wissenschaftliche Buchgesellschaft 1970, S. 22-37, hier S. 22. Siehe hierzu auch meinen Aufsatz: Ein Fest des Intellekts, ein Fest der Lust. Hugo Friedrich, Paul Valéry und die Philologie. In: Jahrbuch der Deutschen Schillergesellschaft - Internationales Organ für neuere deutsche Literatur (Göttingen) LVII (2013), S. 290-321. 
dischen Antike ererbten Topoi zum Besten, zumindest auf implizite Weise. Denn das Glück, so kommentiert er, erfreue uns, aber das Unglück belehre uns, mache uns mithin klüger oder weiser. Das ist nicht etwa eine Aussage, die uns darauf aufmerksam machen soll, dass Glück die Menschen immer dumm und Unglück die Menschen immer klug mache. Dies wäre eine Überlegung durchaus populären Zuschnitts nach dem Motto „Lieber glücklich und dumm als unglücklich und intelligent“. Es handelt sich vielmehr um einen philologisch-philosophischen Gemeinplatz und Hinweis auf die spätestens von keinem Geringeren als Horaz in die literaturtheoretische Diskussion eingebrachte Auffassung und Weisheit, dass die Literatur zu erfreuen und zu bilden habe: „Plaire et instruire“, wie man seit der französischen Klassik auf Neufranzösisch sagt.

Bernardin de Saint-Pierre greift an dieser Stelle folglich auf eine lange literarische Tradition und auf einen keineswegs revolutionären Leitsatz zurück, so wie Paul et Virginie ja das gänzlich Neue nicht auf ganzer Linie, sondern lediglich in bestimmten Aspekten des Textes präsentiert, die wir uns in der Folge noch näher anschauen werden. Allerdings darf man an der Aussage zweifeln, dass man aus dem zweiten Teil des Romans mehr Lehren ziehen könne als aus dem ersten. Es sei denn die Lehre, dass auch eine Utopie, und sei sie noch so schön, doch wiederum auf den Boden dieses Globus zurückgeholt wird, und dass jedem Teil sein Gegenteil entspricht. In jedem Fall läuft die Zweiteilung des Romans in der zitierten Passage zusammen und es bildet sich ein symmetrischer Aufbau des gesamten Erzähltextes heraus, der bis in die kleinsten Details sorgsam und sorgfältig ausgeführt wird. Auf diesem gleichsam klassischen Kompositionswillen beruht - so scheint mir - in wesentlichen Teilen und gemeinsam mit dem (für ein französisches Lesepublikum) exotischen Setting der große Erfolg des Romans.

Unserem expliziten Autor gelingt es, den Erzähler zum Weitererzählen zu bewegen. Und so wird es nach Mitternacht wieder Tag, und die Anführungszeichen häufen sich, da nun die mündliche Rede des Erzählers in ihrer Mitte wieder der mündlichen Rede (und der Stimme) des jungen Herren Raum gibt. Der ist übrigens ein Herr auch in dem Sinne, dass er als junger „maître“ Marie als seine Sklavin besitzt. Denn das französische Kolonialsystem war im 18. Jahrhundert ganz selbstverständlich mit der Sklaverei verbunden und wäre ohne die Ausbeutung von Sklaven nicht vorstellbar und wirtschaftlich hochprofitabel gewesen.

Marie aber sitzt auf einem Felsen in einer typisch philosophischen Haltung, was nichts Gutes ahnen lässt. Das weiß auch Paul, und die Erkenntnis trifft ihn wie ein Schlag. Seine bange Frage, wo denn Virginie, die jungfräuliche Freundin seines Herzens sei, wird mit einem noch bangeren, tränenerfüllten Blick auf das Meer beantwortet. Die Szenerie ist nicht allein auf die Gegenwart, sondern auch auf die Zukunft bezogen. Wir haben ja schon gehört, dass Virginie zwei Jahre 
später an eben jener Stelle unweit der rettenden Küste ihrer Heimatinsel untergehen wird, ohne dass sich die beiden Liebenden noch einmal bei lebendigem Leib in die Arme nehmen können.

Die bitteren Tränen der Sklavin künden das kommende Unheil an. Im Grunde wird damit die Flüssigkeit des Meeres metonymisch ebenfalls als Salzlösung Tränen und Meere sind salzig - mit dem Körper-Leib in Verbindung gebracht, so dass es aus Marie nur so herausquillt. An die Stelle der Sprache ist die Sprachlosigkeit, der beredte Körperausdruck getreten. Darum muss auch Paul stille bleiben. Wir könnten an dieser Stelle im „Préromantisme“ von Bernardin de Saint-Pierre den klassischen romantischen Vers aus Lamartines Gedicht Le Lac schon anklingen lassen. Er passt für die meisten romantischen Texte und lautet: „Un seul être vous manque / et tout est dépeuplé“ („Ein einziges Wesen fehlt Euch / und alles ist entvölkert"). So einfach ist das: Eine einzige Figur, zumeist jene der geliebten Frau, scheidet aus welchen Gründen auch immer aus, und schon ist alles öde und lässt der Melancholie, der Krankheit des Jahrhunderts, dem „mal du siècle“, allen Raum! Es ist eine Krankheit, die von innen kommt und das Subjekt sprachlos macht. Es gibt keine Worte mehr angesichts einer Sonne, die sich für immer

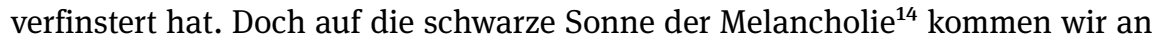
späterer Stelle ausführlich zu sprechen.

Wir könnten dieser Passage noch eine Vielzahl anderer Aspekte und Züge abgewinnen: Nicht uninteressant ist etwa die Tatsache, dass es kein anderer als der Erzähler war, der Paul im Grunde aus dem Verkehr gezogen hatte und damit den Weg dafür bereitete, dass sich die beiden Liebenden nicht mehr voneinander verabschieden konnten. So hat dieser Erzähler folglich allen Grund, an die Geschichte von Virginie und Paul mit Trauer und Melancholie zurückzublicken. Eigentlich ist unser Erzähler mitschuldig an der nun folgenden Tragödie geworden, was im Grunde zwischen seinen Worten, zwischen seinen Zeilen lesbar wird. Ist sein Erzählen nicht eine direkte - und vielleicht auch heilende - Reaktion auf dieses Schuldig-Werden am Unglück derer, die im Zentrum seiner Erzählung und letztlich unseres Romans stehen?

Doch die psychologisch heilsame Wirkung der Literatur ist nicht so einfach zu haben. Denn nicht umsonst will er die Erzählung seiner Geschichte just an jener Stelle beenden, an der er selber sich viel Schuld auflud. Sein Lebenswissen zu versprachlichen, fällt ihm nicht leicht. Es bedarf großer Energie, aber auch einer kunstvollen Bearbeitung, einer Kunst des Erzählens, um eine Heilung durch das Sprechen der eigenen Worte zu bewirken - vergleichbar mit der Situation der Psychoanalyse, in welcher das Finden der eigenen Worte in der Tiefe des Sub-

14 Vgl. hierzu Kristeva, Julia: Soleil noir. Dépression et mélancolie. Paris: Gallimard 1987. 
jekts der Schlüssel zur Heilung moderner Subjektivität ist. Wir stoßen hier auf die Tatsache, dass der Erzählvorgang selbst etwas mit der Tiefendimension moderner Subjektivität und mehr noch mit der Situation des Subjekts in der Moderne zu tun hat. Es geht - um mit dem Titel eines autobiographischen (und psychoanalytisch eingefärbten) Textes von Marie Cardinal zu sprechen - um Les mots pour le dire. ${ }^{15}$ Und es ist die Aufgabe des Auctors, wie ein Psychoanalytiker dem Erzähler diese Worte zu entlocken.

$\mathrm{Zu}$ Ihrem Trost darf ich freilich noch hinzufügen: Der arme Paul sieht das Entschwinden der Geliebten dann doch noch, und zwar von einem hohen Berg seiner Heimatinsel aus, von wo er gewiss nicht mehr seine Virginie selbst, wohl aber ihr Schiff auf dem Weg nach Frankreich in zehn Seemeilen Entfernung verfolgen kann. Wir haben ja bereits Bernardin de Saint-Pierres Vorliebe für die Gebirgswelt von Mauritius gesehen und auch die Kenntnisse des studierten Ingenieurs, der etwas von trigonometrischen Abstandsmessungen verstand. Doch bei diesem Sehen aus der Ferne ist die Sprache ausgeschaltet, ein böses Vorzeichen für die Zukunft beider Liebender. Natürlich ist der Ort, von dem aus Paul auf das Meer blickt, ein romantischer Ort par excellence; aber auf diesen Aspekt erhoffter Transparenz kommen wir noch später zu sprechen. Dort findet sich an den Gebirgsabhängen auch jener „Wald in der Luft“, „dans l'air“, der einen Alexander von Humboldt an den Naturbeschreibungen des französischen Schriftstellers so sehr entzückte. Denn er hatte verstanden, dass mit Bernardin de Saint-Pierres Beschreibungen der tropischen Natur zugleich auch erstmals eine Ästhetisierung einer außereuropäischen Bergwelt begonnen hatte. Jean-Jacques Rousseaus Ästhetisierung der Schweizer Alpen war nun, schon nach wenigen Dekaden, ergänzt um eine ästhetische In-Wert-Setzung tropischer Gebirgswelten.

Lassen Sie uns zu einer zweiten Passage dieses Textes kommen, welche bereits die Zeitgenossen Bernardins begeistert hat: Es ist die Szene des Schiffbruchs mit Zuschauer, in der Virginie in den Fluten versinkt und spektakulär ertrinkt! Ihr Schiff ist unmittelbar vor der Küste der Insel Mauritius in einen verheerenden Sturm und in Seenot geraten. Die Mannschaft steht im Begriff, das Schiff mit seinen geladenen Gütern, aber auch mit all seinen Passagieren zu verlassen und sich an Land zu retten. In dieser Situation blenden wir uns ein und sehen eine der berühmtesten Todesszenen, die Sie - wenn Sie sie noch nicht kennen - vielleicht nie mehr vergessen werden. Schauen Sie also gut zu, wie sich zunächst am Ufer die erzähltechnische Kameraperspektive auf Paul richtet:

15 Vgl. Cardinal, Marie: Les mots pour le dire. Paris: Grasset et Fasquelle 1975. 
Kaum hatte dieser junge Mann den Gebrauch seiner Sinne wiedererlangt, stand er auf und drehte mit neuer Inbrunst sich dem Schiffe zu, welches das Meer unterdessen mit schrecklichen Schlägen zu öffnen begann. Die ganze Mannschaft, die nun an ihrer Rettung verzweifelte, stürzte sich in ihrer Masse ins Meer, klammerte sich an Kisten, Hühnerkästen und Planken, an Tische und Fässer. Dann aber erblickte man einen Gegenstand, der eines ewigen Mitleids würdig war: Ein junges Fräulein erschien achtern auf der Galerie der SaintGéran und streckte ihre Arme dem entgegen, der sich so unendlich bemühte, sie zu erreichen. Es war Virginie. Sie hatte ihren Geliebten an dessen Unerschrockenheit erkannt. Der Anblick dieser liebreizenden Person, die einer so grässlichen Gefahr ausgesetzt war, erfüllte uns mit Schmerz und Verzweiflung. Virginie aber, in ihrer edlen und sicheren Haltung, machte uns mit der Hand Zeichen, als wollte sie uns noch ein ewiges Adieu zuwerfen. Alle Seeleute hatten sich ins Meer geworfen. Allein ein einziger war noch auf der Brücke geblieben, gänzlich nackt und muskulös wie Herkules. Respektvoll näherte er sich Virginie: Wir sahen, wie er sich zu ihren Knien warf und sich bemühte, sie ihrer Kleider zu entledigen; sie aber wies ihn mit Würde zurück und wandte ihr Gesicht von ihm ab. Alsbald waren die verdoppelten Schreie der Zuschauer zu hören: „Retten Sie sie, retten Sie sie; verlassen Sie sie nicht!“ Doch in diesem Augenblick türmte sich abgrundtief ein Gebirge an Wasser von furchtbarer Größe zwischen der Insel Ambre und der Küste auf und lief brüllend auf das Schiff zu, das es mit seinen schwarzen Flanken und schaumsprühenden Gipfeln bedrohte. Bei diesem schrecklichen Anblick sprang der Seemann alleine ins Meer; und Virginie, den sicheren Tod vor Augen, legte eine Hand auf ihre Kleider und die andere auf ihr Herz, und als sie ihre heiteren Augen nach oben erhob, glich sie einem Engel, den Flug gen Himmel erhebend. ${ }^{16}$

Diese eindrückliche Passage, die zu den berühmtesten der französischen Literaturgeschichte zählt, ist ungezählte Male in der Malerei, aber auch in anderen Künsten, im Film und auf der Bühne immer wieder neu in Szene gesetzt worden. Virginie macht hier ihrem Namen - nomen est omen - alle Ehre und bewahrt vor aller Augen ihre Jungfräulichkeit, die sie selbst um den Preis ihres Lebens nicht einmal bis zum Punkt nackter Unkeuschheit gefährden will. Sie ist von Adel, und ihre Haltung zeugt zugleich von Seelenadel; ihren Körper schützt sie bis in den Tod vor allen Blicken, selbst von jenen, die ihr Leben retten könnten. Sie ist ganz einfach nicht von dieser Welt und steigt daher - zumindest in der Literatur engelgleich gen Himmel auf.

Wir haben in dieser wohlkalkulierten Todes- und Abschiedsszene die Szenerie eines Schiffbruchs mit Zuschauer vor uns, die seit der abendländischen Antike, genauer seit Lukrez, stets einen bevorzugten Ort philosophischer Reflexion darstellte. Der Schiffbruch allein bildet diesen Reflexionsort noch nicht: Es müssen auch ein oder mehrere Zeugen hinzutreten. Von größter Bedeutung ist in diesem Zusammenhang die Tatsache, dass diese Zeugen im Grunde nicht mehr in die

16 Saint-Pierre, Bernardin de: Paul et Virginie, S. $202 \mathrm{f}$. 


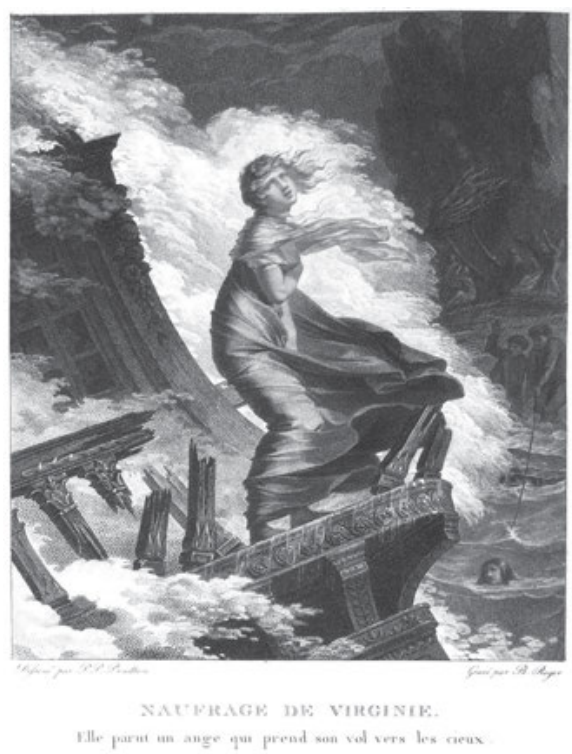

Abb. 13b: „Naufrage de Virginie“, Abbildung aus Paul et Virginie, 1806.

eigentliche Handlung, ins Geschehen eingreifen können und daher notgedrungen zu simplen Zuschauern werden; sie geraten auf diese Weise in eine philosophische, den Weltengang also nicht direkt durch Handeln verändernde Position.

Das spektakuläre Ende der jungen Frau ist dabei in mehrfacher Weise bedeutsam. Wie so oft in der Romantik verläuft die Handlung über den weiblichen Tod, also Nur über ihre Leiche. ${ }^{17}$ Wir werden die vielfältigen Variationen dieser fundamentalen Szenerie ein ums andere Mal in unserer Vorlesung sehen, bisweilen auch mit nationalen Allegoresen gepaart, für welche die weiblichen Titelfiguren die maßgeblichen Projektionsflächen darstellen. Virginie jedenfalls bewahrt ihre Keuschheit, indem sie sich weigert, sich entkleiden zu lassen, um so schwimmend das rettende Ufer noch erreichen zu können.

Denn in den Kleidern, die man damals als junge Dame aus gutem Hause trug, wäre ein Schwimmen in der Tat nicht möglich gewesen. Nicht ganz unbedeutend ist bei alledem die Tatsache, dass der letzte Mann an Bord ein wahrer Herkules ist, also der Inbegriff des antiken und damit vorchristlichen Mannes schlechthin, dem Virginie ihre weibliche - und ich füge hinzu: ihre christliche - Unschuld ent-

17 Vgl. Bronfen, Elisabeth: Nur über ihre Leiche. Tod, Weiblichkeit und Ästhetik. München: Deutscher Taschenbuch Verlag 1994; sowie dies. (Hg.): Die schöne Leiche. Weibliche Todesbilder in der Moderne. Wien: Goldmann 1992. 
gegenstellt. So wird gleichsam das antike Modell verabschiedet und macht einer christlichen Imago Platz, die in der Tat besondere Positionen für die Frau bereithält. Virginie steht in diesem Zusammenhang für eine christliche Körperkultur, für ein christliches Verständnis des weiblichen Körpers, welcher als aufsteigender Engel schließlich entsexualisiert wird. Denn Engel haben, wie Sie ja wissen, kein Geschlecht.

Doch auch wenn Virginie am Ende ihres Weges als Engel kein Geschlecht mehr besitzt, sind doch die Geschlechterrollen in dieser Inszenierung klar verteilt. Dies betrifft keineswegs nur den Gegensatz zwischen der unschuldigen jungen Frau, die hilflos den Gewalten ausgeliefert ist, und dem muskulösen Mann, der sich in dieser Szenerie wohl retten und damit den Gewalten trotzen kann, in seinem Wert als Mann der unberührten Weiblichkeit aber himmelweit unterlegen ist. Da ist alle muskelgewappnete Schönheit des herkulischen Mannsbilds vergebens - dieser Herkules weiß dies auch und begegnet der absoluten Weiblichkeit mit unterwürfigem Respekt. Er tut dies nicht allein auf Grund von Virginies adeliger Herkunft, welche die Standesgrenzen zwischen beiden aufzeigt, dem jungen Fräulein und dem einfachen Matrosen, sondern weit mehr noch wegen ihres Seelenadels, der allem profan am Leben Klebenden bei weitem überlegen ist.

Es ist ein engelhaftes Geschöpf, das hier in weißen Kleidern den Zuschauern und damit auch der Leserschaft - noch einen letzten Abschiedsgruß entbietet. Virginie ist unschuldiges Kind und zugleich auch - dies belegt ihr Zurückweisen jeglicher Entblößung - körperlich reife Frau. Beide Aspekte werden dargestellt in Form eines Gehorsams gegenüber den inneren Werten, wie sie gerade auch die Mädchenerziehung in Europa, speziell in Frankreich, felsenfest in ihr verankert hat. Im Grunde ist Virginie bereits an dieser Stelle unüberbrückbar entrückt: Eine unüberwindliche Distanz schiebt sich zwischen die beiden Liebenden und lässt sie als zu groß erscheinen, als dass ein Eingreifen, ein Handeln überhaupt noch möglich wäre.

Wir erkennen in dieser Szenerie erneut die Wiederaufnahme des Motivs der optischen, nicht aber sprachlichen und schon gar nicht körperlichen Kommunikation, welche schon die nicht stattgefundene Abschiedsszene charakterisierte, bei der Paul seine angebetete Virginie nur noch von weitem entschwinden sah. So muss sich später auch in Paul ein wahrer Abgrund an sprachloser Melancholie auftun. Nach dem wortlosen Abschied, der keiner war, ist das Schiff aus Frankreich nun zurückgekehrt, aber nur, um Virginies Tod wahrhaft dramatisch in Szene zu setzen. Die beiden Liebenden sind und bleiben voneinander getrennt.

Doch es gibt durchaus Kommunikation in dieser Abschiedsszene: Die Verständigung zwischen den Schiffbrüchigen und den Zuschauern am sicheren Ufer hat etwas Absurdes, denn Virginie wird es in dieser Szene nur mehr möglich sein, 
sich als unschuldiges Opfer eines Schicksals zu präsentieren, auf das sie keinen Einfluss hat und das sie klaglos auf sich nimmt. Sie spielt eine Rolle, die ihr bereits seit dem Brief der Erbtante in hohem Maße zugewachsen ist: bloße Figur auf dem Schachbrett des Schicksals, der von ihr unabhängigen Fügung zu sein und nicht dagegen angehen zu können. Sie wird von einer unbarmherzigen Kolonialgesellschaft wie von ihrer genderspezifischen Erziehung in eine weibliche Passivität gezwungen, der sie nicht mehr entfliehen kann, sondern die sie engelgleich annimmt. Damit aber wird auch Paul letztlich zum Opfer einer ständisch verfassten Kolonialgesellschaft, die als Hort der weit entfernten ,Zivilisation“ die Träume der beiden jungen Heranwachsenden zerstört.

Das präzise parallele Arrangement dieser Szenerie stellt den letzten emotionalen Höhepunkt vor dem dumpfen und dunklen Lauf der sich nun ausbreitenden Melancholie dar. Diese hatte schon zuvor ihr unheilvolles Spiel begonnen und sich bereits im Bernardin'schen „Préromantisme“ als „mal du siècle“ mit aller zerstörerischen Kraft zu erkennen gegeben und zeigt Bernardin de Saint-Pierre als sorgfältig konstruierenden Schriftsteller, dem der Weg von den Naturstudien in den Kernbereich romantischer „écriture“ gelungen ist. Der Verfasser von Paul et Virginie hat im Grunde seinen Roman nicht nur zweigeteilt, sondern ihm auch eine ausgeprägt symmetrische, eigentlich spiegelbildliche Achse mitgegeben, welche die Grundordnung dieses Romans und damit trotz aller Zerstörungen auch die ordnende Kraft literarischer Gestaltung darstellt.

Dieser ästhetische Gestaltungswille ist in Bernardin de Saint-Pierres Schreiben und Denken allgegenwärtig. Stets liegt ihm ein Weltentwurf zu Grunde, der auf Harmonie abzielt, auf eine Balance der positiven und der negativen Kräfte, die sich letztlich wie mit naturgesetzlicher Konsequenz ausgleichen, auch wenn in Paul et Virginie auf den ersten Blick die negativen, zerstörerischen Impulse zu dominieren scheinen. Diese ordnende Kraft, die wir als Kosmos in einem doppelten Sinne begreifen dürfen - nämlich Kosmos als dem Chaos entgegen stehende Ordnung und Weltordnung sowie als Schmuck und Ästhetik -, findet sich auf den verschiedensten strukturellen Ebenen des kurzen Romans, ebenso auf der Ausdrucks- wie auf der Inhaltsebene. So etwa in dem sehr präzise dreidimensional angeordneten Garten, den Paul gleichsam sphärenartig um ein Zentrum herum aufbaut und von dem am Ende des Textes, wenn der narrative Mikrokosmos zusammengebrochen sein wird, nur noch wenige Bruchstücke als zeugnishafte Ruinen übrigbleiben werden.

Doch Bernardin de Saint-Pierre hat diese kosmische Ordnung nicht nur auf die Ebene seines Romans und den romanesken Mikrokosmos bezogen, sondern auch im Großen gedacht. Es ging ihm stets in seinen - wie später des Öfteren gesagt wurde - naturwissenschaftlichen Träumereien, in seinen Etudes de la Nature wie in seinen Harmonies de la Nature, um die Herstellung einer vollkom- 
menen Ordnung des Weltalls. Die grundlegende Bewegung ist hierbei die der Synthese: Die einzelnen Teile und Partien werden stets aufeinander bezogen, miteinander organisch verbunden. Dieses Element der Synthese steht genau jenem der zerteilenden Analyse der Aufklärung, der „Lumières“ gegenüber; ${ }^{18}$ denn dort herrscht eine unterteilende Rationalität vor, welche gleichsam die Dinge immer weiter analysiert und damit zertrennt, zweiteilt, um danach das Zweigeteilte weiter zweizuteilen und neuerlichen Analyseverfahren zu unterwerfen. Bei Bernardin de Saint-Pierre tritt nunmehr die Synthese an die Stelle der Analyse. Damit ist ein entscheidender Schritt - so scheint mir - weg von der Analytik der Aufklärung hin zur Synthese der Romantik getan, ein epistemologischer Wandel, mit dem wir uns noch mehrfach beschäftigen werden.

Waren die Etudes de la Nature gleichsam die Vorstudien, die Fingerübungen späterer Unternehmungen - wie sie es schon im Titel aussagten -, so sollten seine Harmonies de la Nature, die nur selten untersucht wurden - Racaults brillante Studie macht hier eine Ausnahme ${ }^{19}$ - jenen Versuch einer letztendlichen Synthese aller Dinge unternehmen, die sich zu einem Weltganzen anordnen lassen. So finden wir im dritten Band dieser Harmonies, die nun auch den Blick weit über das Erdenrund hinaus lenken und in die Welt der Planeten - den Kosmos eben - schauen eine Vision, die Alexander von Humboldt gewiss interessiert und angeregt haben dürfte. Bernardin de Saint-Pierre entfaltet darin eine Weltsicht, die letztlich heliozentrisch ist und alles von der Sonne ableitet. Er dissertiert und spekuliert über unsere Milchstraße und ihre Planeten und nicht zuletzt über deren Bewohner. Ein Beispiel? Nun, im Folgenden geht es um die Bewohner des Saturn:

All diese planetarischen Körper bieten indes ihren Zuschauern keinerlei isolierte und allzeit permanente Perspektiven; sie sehen den doppelten Ring von mehr als neuntausend fünfhundert Meilen Breite mit all seinen Kontinenten, seinen Meeren, all seinen Gebirgen, seinen Inseln und mit seinen Flüssen, und mit einem Durchmesser von mehr als zweihunderttausend Meilen unter ihren Augen in zehn Zeitstunden vorüberziehen. Ihr Entzücken ist tausendfach größer als das eines Menschen, der sich niemals von seinem Dorf entfernt hat und zum ersten Male einen Bericht von einer Reise in die Südsee liest und der binnen weniger Stunden in seinem Geiste die Welt umrundet. Sie müssen auf beiden Seiten ihres Ringes Effekte sehen, welche in beiden Hemisphären unseres Globus existieren und welche das menschliche Auge nicht gleichzeitig erfassen kann; sie müssen darin noch zwei Atmosphären sehen, eine obere und eine untere, und Inseln und Ketten von Gebirgen, die an

18 Vgl. hierzu auch Racault, Jean-Michel: Balzac, Bernardin de Saint-Pierre et l'héritage des Lumières: problèmes de sources et d'orientation dans „Le vicaire des Ardennes“. In: L'Année Balzacienne (Paris) 8 (1987), S. 201-226.

19 Vgl. Racault, Jean-Michel: La cosmologie poétique des „Harmonies de la Nature“. In: Revue d'Histoire Littéraire de la France (Paris) LXXIX, 5 (septembre - octobre 1989), S. 826-842. 


\begin{abstract}
ihrer Basis zusammenlaufen. Wenn sie einen Herschell haben, so müssen sie in einander so nahen Landstrichen Flüsse, Herden, Wälder, Liebende und Geliebte unterscheiden, die an ihren Füßen entgegengesetzt sind und die sich an den Extremitäten ihres Ringes die Hände reichen [...]. Schäfer und Schäferinnen, die im Kreis um einen Maien tanzen, den sie gepflanzt, oder junge Burschen und junge Mädchen, die aus Freude rund um ein großes Mühlrad für Weizen springen, den sie geerntet, sie alle haben keine so abwechslungsreichen wie grazilen Bewegungen wie jene Königinnen der Nacht, rund um den Globus, den sie erhellen und den sie befruchten. ${ }^{20}$
\end{abstract}

In derlei Passagen geraten die Ordnungsprinzipien des Kosmos zu kosmischen Träumereien, in welchen die Planeten unseres Sonnensystems zu Projektionsflächen lieblicher Fiktionen werden. Die Zahlenangaben in dieser Passage mögen belegen, dass der französische Schriftsteller und Naturforscher in seinen Harmonies de la Nature durchaus den Anspruch nicht aufgegeben hat, nachprüfbare, wissenschaftliche Aussagen über die Natur zu treffen und seine Annahmen bezüglich anderer Planeten entsprechend quantitativ zu belegen. Und in der Tat gehen seine Beschreibungen aus von Messungen der Saturnringe - etwa von Herschell - und Analysen des planetarischen Systems, die er sehr wohl zur Kenntnis genommen hat und seinem Lesepublikum nun vorstellt. Wir finden in den Harmonies ein Vorhaben vor, das auf einer nicht länger fiktionalen, sondern empirisch ausgerichteten Grundlage Alexander von Humboldt gegen Mitte des 19. Jahrhunderts in seiner Summa, seinem oft als „Alterswerk“ bezeichneten Kosmos in fünf Bänden umsetzte. Der unermüdliche, ständig mit seinen Messungen beschäftigte, aber stets um eine generelle Sichtweise bemühte Preuße wurde ebenso wie der spekulative, seine Naturphilosophie mit Fiktionen verbindende Franzose mit seinem gewaltigen Werk zu Lebzeiten nicht mehr fertig.

Wenn wir die Schriften Bernardin de Saint-Pierres in ihrer Gesamtheit heranziehen, so können wir nicht übersehen, dass für ihn nicht mehr länger die „raison“ der Aufklärer, sondern das „sentiment“ der Frühromantik die beherrschende Kraft bei der geistigen Durchdringung und Darstellung der Kräfte der Natur ist. Zugleich begreifen wir bei genauerer Lektüre, dass Bernardin de SaintPierre seinen Blick nicht von der Erde aus auf Saturn, sondern gleichsam vom Saturn aus auf die beiden Ringe wirft. In ihnen spiegeln sich wie in einem großen Panorama die Kontinente, Inseln, Meere, Wälder und so viele andere Bilder, dass in einer liebevollen Fiktion eine eigene Welt in diesem Universum der Planeten entsteht.

20 Saint-Pierre, Bernardin de: Harmonies de la Nature. Bd. III. Paris: Chez Méquignon-Marvis 1818, S. 385 f. 
In Bernardins Sonnensystem kreist alles um die allein lebensspendende Sonne, die für jegliche Energie und deren Ansammlung in Form von Gold im Erdinneren verantwortlich ist. Der ganze Kosmos innerhalb dieses heliozentrischen Systems ist belebt: Jedes Ding, jede Pflanze, jedes Tier, aber natürlich auch jeder Planet besitzt seine eigene Finalität, seine eigene „raison d'être“, seinen eigenen Zweck innerhalb dieses Systems von Gewichten und Gegengewichten, welches die Harmonies de la Nature enthüllen wollen. Auch in dieser Variante seines Schreibens projiziert Bernardin de Saint-Pierre Elemente einer Idylle, eigentlich einer Pastorale, also einer Schäfer-Idylle in die vielen fremden Welten, die doch ihrerseits nur andere Ausdrucksformen und andere Gegenwelten der großen Erdenwelt darstellen. Denn der Bezugspunkt für Bernardins galaktische Fiktionen ist und bleibt der Planet Erde.

Der Leitfaden für diese Vorstellungen ist - wie bereits betont - nicht die „raison“, sondern das „sentiment“, ein Mit-Fühlen, das es Bernardin de SaintPierre erlaubt, gleichsam durch Introspektion die fremden Welten zu konstruieren. Die kalte Vernunft der Aufklärer, so scheint es, hat bei ihm abgedankt: Er stellt sie in der Nachfolge von Jean-Jacques Rousseau und damit ausgehend von der Genese moderner Subjektivität in Frage. Wir könnten diesbezüglich von einer Erweiterung der Vorstellung des Genfer Philosophen sprechen: „Je sens mon cœur et je connais les hommes“. Und dies gilt selbst für die menschenähnlichen Wesen, die sich auf anderen Planeten tummeln. In solchen Passagen wie den angeführten sieht Bernardin nämlich in sich hinein und erblickt verständnisvoll fremde Welten: „Je sens mon cœur et je connais les mondes“, so könnten wir daher formulieren. Es überrascht aus unserer heutigen Perspektive nicht, dass derartige Vorstellungen im Verlauf des 19. Jahrhunderts nur allzu schnell am Wegesrand der Wissenschaftsgeschichte liegengelassen wurden in dem Maße, wie sich die verschiedenen Wissenschaften, wissenschaftlichen Disziplinen und Wissenschaftsdiskurse immer weiter ausdifferenzierten. Und doch: Die KosmosIdee ist damit noch keineswegs ausgeträumt, ausgeräumt und verschwunden. Sie kehrt verändert in eben jenem Alexander von Humboldt wieder, der ihr um die Mitte des 19. Jahrhunderts von Potsdam und Berlin aus noch ein letztes Mal - ein vorerst letztes Mal - ein gewaltiges Denk- und Schreibgebäude widmete, in dem ebenfalls die Planeten, das Weltall, „Himmel und Erde, alles Geschaffene“ nicht fehlen durften.

Lassen Sie mich zum Abschluss unserer Beschäftigung mit dem RousseauSchüler Bernardin de Saint-Pierre aber noch auf jene Kraft zurückkommen, die im Zentrum der Konstruktion von Paul et Virginie steht und die auch in einem ganz kosmologischen Sinne die Welt im Innersten zusammenhält. Es ist ganz zweifellos die Liebe, vielleicht genauer aber noch die „sensibilité“, die Empfindsamkeit, die zum Signum jener Übergangszeit zwischen „Lumières“ und dem 
deutschen Klassizismus einerseits, „Préromantisme“ und Romantik andererseits wurde und zwischen diesen beiden Polen vermittelt. Und diese besonderen Kräfte sind im Sinne Bernardin de Saint-Pierres gänzlich undenkbar ohne die Frauen, die im Übrigen - das sollten wir nicht vergessen - einen nicht unbeträchtlichen Teil des Bernardin'schen Lesepublikums ausmachten. Kein Wunder also, wenn er sich gleich mehrfach an sie wandte und immer wieder ihre Tugenden und ihre verbindenden, harmonisierenden Kräfte beschwor. Schauen wir uns dazu einen Auszug aus seinem „Préambule“ zur Ausgabe von 1806 näher an:

Doch die Frauen haben mehr als die Philosophen dazu beigetragen, die Nationen zu formen und zu reformieren. Sie erblassten keineswegs des Nachts, wenn sie lange Abhandlungen über die Moral verfassten; sie stiegen keineswegs auf Tribünen, um donnernd die Gesetze erschallen zu lassen. In ihren Armen war es, wo sie die Männer das Glück spüren ließen, im Kreise des Lebens einmal glückliche Kinder, dann treue Liebhaber, schließlich zuverlässige Ehemänner und tugendhafte Väter zu sein. Sie waren es, welche die ersten Fundamente für das Naturrecht legten. Die erste Gründerin einer menschlichen Gesellschaft war die Mutter einer Familie. [...] Sie sind die ersten und die letzten Apostel jeglichen religiösen Kultes, den sie ihnen von zartester Kindheit an eingeben. Sie erfüllen den gesamten Lauf ihrer Leben mit Schönheit. [...] Sie waren es, die das Brot, die geschmackvollen Getränke, die Stoffe unserer Kleidung, die Spinnereien, die Gewebe und vieles mehr erfanden. [...] Um den Männern zu gefallen, erfanden sie die frohen Lieder, die unschuldigen Tänze und inspirierten ihrerseits die Poesie, die Malerei, die Bildhauerei, die Architektur in all jenen unter ihnen, welche von diesen Frauen kostbare Erinnerungen zu behalten wünschten. [...]

In der Tat besitzt jeder liebenswerte Gegenstand seine venusische Fülle, das heißt einen Teil jener unbeschreiblichen Schönheit, welche die Liebe inspiriert. Zweifellos ist der berührendste unter allen die Empfindsamkeit, diese Seele der Seele, welche alle Fähigkeiten belebt. Ihr ist es zu verdanken, dass sich Venus den unbeherrschbaren Gott des Krieges unterwarf. ${ }^{21}$

Diese lange, von mir allerdings stark gekürzte Passage, die sich über viele Seiten des Vorworts zur Ausgabe von 1806 hinzieht, enthält eine wahre Apologie der Frauen, einen „Eloge des femmes“, in dem die Frauen unter anderem zum eigentlichen Zement der Welt erklärt werden, der die Gesellschaft der Männer zusammenhält. Erst durch die Frauen werden im Grunde das Aufkommen und die Zirkulation der Ideen und Vorstellungen ermöglicht und jener Wert in den Mittelpunkt gerückt, um den bei Bernardin de Saint-Pierre alles kreist: das Leben, und zwar in all seinen Schattierungen. Denn wie der geringste, unwichtigste Teil der Ding-Welt ist auch der gesamte Kosmos, alles Geschaffene in seiner Ordnung und Schönheit, von Leben erfüllt. Und ganz, wie die Planeten um die Sonne kreisen,

21 Saint-Pierre, Bernardin de: Paul et Virginie, Préambule, S. 57-60. 
so steht im Mittelpunkt des menschlichen Lebens für Bernardin de Saint-Pierre die Frau.

Denn erst die Frauen sind als die eigentlichen Erfinderinnen all jener Künste $\mathrm{zu}$ begreifen, die auf positive, hervorbringende Werte gerichtet sind, auch wenn sie - und dies ist wichtig - für Bernardin vor allem den Schmuck des Lebens der Männer darstellen sollen. Kein Zweifel: Der „Eloge“ ist eingebaut in eine patriarchalische Gesellschaftsordnung, wie sie für das ausgehende 18. wie das gesamte 19. Jahrhundert im Abendland unangefochten herrschte. Diese Reduktion der Geschlechterrolle auf eine Verschönerungsdimension erkauft gleichsam jene Apotheose der Frau, die auf ein Gleichgewicht der Welt auf Basis eines Gleichgewichts der Geschlechter gerichtet ist. Wir haben es mitnichten bei Bernardin de Saint-Pierre mit einer Revolution der Geschlechterbeziehungen zu tun.

So überrascht es auch nicht, wenn die „sensibilité“, die Empfindsamkeit, gerade den Frauen als eine besondere Stärke zufällt, zu der letztlich auch die Liebe gehört, die es vermag, selbst die männlich-zerstörerische Kraft des Kriegsgottes zu brechen. Was Bernardin de Saint-Pierre auf diesen Seiten entfaltet, ist nichts anderes als die zivilisatorische Mission der Frau: Bei ihr sieht er den Ursprung all jener gesellschaftsbildenden und zivilisierenden, im Grunde erst zivilisatorischen Werte, zu denen er neben den Künsten die Religion - und vielleicht mehr noch das „sentiment religieux“ - zählt. Die Frau verkörpert damit die gesellschaftlichen Bindekräfte, jene Kräfte also, die auch für den Zusammenhalt der menschlichen Gesellschaft überhaupt verantwortlich sind. Gesellschaft wird erst zur Gemeinschaft durch das Weibliche, durch die „sensibilité“, die Empfindsamkeit der Frau.

Was aber geschieht nun in einer Welt, in der diese Bindekräfte, diese Kräfte des Zusammenhaltens der Welt aufs Äußerste gefährdet sind, in einer Welt, in der die Moderne mit ihrer zunehmenden Säkularisierung aller Lebensbereiche grundlegende Risse in die vermeintliche Einheit hineingetrieben hat, welche die Gesellschaft des Ancien Régime noch zu binden schien? Was sind also die Aufgaben und die Rollen der Frau, der Liebe, der Empfindsamkeit in einer Gesellschaft, die ihre transzendente Legitimation, ihre Gottgegründetheit, verloren hat und durch den Prozess der Aufklärung hindurchgegangen ist?

Auf diese Fragen sollen uns die Texte der nachfolgenden Autorinnen und Autoren Antworten geben, die es uns erlauben, ein offenes Bild der möglichen Zukünfte im 19. Jahrhundert zu zeichnen. Wir legen dabei den Schwerpunkt zunächst auf europäische Schriftsteller, welche die Handlung ihrer Erzähltexte in die außereuropäische Welt verlagerten und damit in gewisser Weise den Spuren Bernardin de Saint-Pierres folgten. Denn noch bevor wir uns mit Texten außereuropäischer Schriftstellerinnen und Schriftsteller beschäftigen, wollen wir erfahren, welche Bilder und Projektionen es waren, die von Europa aus im Zeichen 
der Romantik auf die außereuropäische Welt geworfen und gerade auch für die Welten zwischen den Wendekreisen im fiktionalen Sinne entworfen wurden. Dabei wollen wir erneut den Normen und Formen des europäischen Kolonialismus, aber auch seinen Gefahren, Risiken und Nebenwirkungen breite Aufmerksamkeit schenken. 